\title{
Wireless Learning Technology in Higher Education - a Case Study in Singapore
}

\author{
Abhishek Bhati \\ Business \& Tourism, JCU Singapore \\ abhishek.bhati@jcu.edu.au \\ Anita Lundberg \\ Arts \& Social Sciences, JCU Singapore
}

\author{
Teoh Teik Toe \\ Information Technology, JCU Singapore
}

\author{
Margaret Carter \\ Education, James Cook University \\ Australia
}

\begin{abstract}
Wireless Learning Technologies (WLTs) are set to replace the traditional methods of information sharing and set the trend for future information presentation and collaborative multiuser sharing. Wireless learning technologies (WLTs) used in education include mobile technologies such as smartphones, tablets and laptops as well as systems designed to be used specifically in technology-rich collaborative learning spaces. Such spaces are networked both technologically as well as through student-to-student interactions.
\end{abstract}

This paper undertakes a literature review of wireless learning technologies for multi-platform compatibility over a multitude of personal devices and operating systems. It discusses the use of WLT for new collaborative spaces of learning. The paper further undertakes a comparative descriptive analysis between a space recently discussed in the teaching and learning literature with a case study of one classroom based on the authorial team's participation and observation.

Index Terms - higher education, learning spaces, networked spaces, Singapore, teaching and learning, wireless learning technology

\section{INTRODUCTION}

$\mathrm{P}$ ROGRESS in the development of wireless learning technologies (WLTs) has influenced all sectors of the economy. The higher education sector, including the learning and teaching arena, has enormous potential to engage wireless learning technologies.

Wireless learning technologies (WLTs) used in education include mobile technologies such as smartphones, tablets and laptops as well as systems developed for use in specifically designed technology-rich collaborative learning spaces. Such spaces are networked both technologically as well as through student-to-student interactions [1].

The aim of these new 'networked' classrooms is thus to create learning spaces that are responsive to a digital and networked world, one that engages both students and academics in collaborative learning and teaching. These spaces facilitate student engagement in order to enhance the learning experience [2].
The authors of this paper have formed a cross-disciplinary, cross-campus research team to study one example of a 'networked' collaborative classroom, including: the space of learning [2], teaching and learning perceptions and practices, and use of WLTs in the classroom. This paper sets out a background to this research project.

\section{THE SINGAPORE CONTEXT}

Singapore is recognized as both a global business as well as education hub. Strategically situated at the cross roads of east and west, and north and south; located between the rising Asian economies of India and China, it sits at the nexus of S-E Asia. It boasts highly established, competitive world ranking national universities and as well as international universities that enter into twinning arrangements or joint partnerships, or establish offshore branch campuses within the nation state. Universities attract Singaporean students as well as international students from the region and exchange students from around the globe.

Within this context of being both an education and business hub, Singapore has many start-up companies, including those developing wireless learning technologies. One such company engaged in the development of WLTs for both business and educational spaces is WOW Vision. Of particular interest to this research is their ProVEOS WLT system [1].

JCU Singapore, the case study of this paper, is one example of an international branch campus (IBC). The campus has recently retrofitted two classrooms with the aim of creating technology rich collaborative learning spaces. One of the classrooms uses Apple WLT systems, the other uses the ProVEOS WLT platform. It is this second 'networked' classroom that forms the basis of this research project.

JCU Singapore, is the offshore campus of James Cook University, an Australian university with tropical campuses located in the north of Australia in the cities of Townsville and Cairns - as well as having its 'capital city' campus in Singapore. Thus, JCU is part of the new phenomena of 'networked' universities. Its specific focus is on being a tri-city university. Drawing on its sense of place and location, the university's research agenda focuses on the tropics. Within the framework of 
a research-teaching nexus, we take the notion of 'sense of place' to include the importance of creating a sense of place within the university's learning spaces - a place that is collaboratively and globally networked.

\section{LITERATURE REVIEW}

Wireless Learning Technology in education includes the subsets of mobile technologies as well as the WLTs systems used in new 'networked' classrooms. Thus the broad term WLTs encompasses the use of: mobile devises such as handheld smart phones, tablets and laptops; WLT platforms installed in fixed spaces such as classrooms using Wireless LAN (WiFi); as well as the use of mobile technologies connecting to classroom WLT platforms. Each of these technologies has formed an active area of research within the teaching and learning arena. The following literature review sets out the broad range of WLTs and approaches to understanding their importance to the future direction of education.

\section{Mobile WLTs}

Mueller, Wood, Pasquale and Cruikshank [3] studied the use of mobile (handheld) devices in higher education. The methodology of longitudinal analysis was adopted in this study. Conducted at one university over one teaching period of sixteen weeks, the researchers documented students' use of one mobile technology, that of the smart phone, in a designated undergraduate subject. Students reported that the smart phone device was easy to use, and they were optimistic regarding its potential role as an instructional tool. The findings indicated that students were self-directed in their use of the device, building their capacity as both interdependent (collaborative) and independent (individual) learners. The students explored smart phone functions and uses beyond the tasks provided by their instructors. They found innovative ways to use the smart phones within and outside of the classroom. Exchange of information and ideas emerged as the single most frequent use of the smart phones. Findings recognized that academic staff need to ensure that clearly defined instructions for the use of smart phones as teaching devices are communicated and explained to students.

It is important to note, however, that although the study supported the use of a handheld device as a learning tool, their use as a "classroom instructional" device for learning and teaching purposes was more limited than student-directed use of the device for social communication (chatting and texting) in and out of the classroom. This study highlighted that the affordances of technology are dependent on high student uptake. Absence of student interest and motivation in the use of technology for learning will reduce the intended positive outcomes of the technology. The researchers suggested that student participation in identifying device uses for learning and teaching purposes increases student participation with the mobile devices [3].

Similarly, Ross, Morrison and Lowther [4] discuss the positive influences of wireless technology on learning experiences in education. Although this study was conducted in the context of a secondary school, it nevertheless has implications for higher education. The study employed a qualitative methodology of interviews to explain the use of new technology tools, such as the iPad, within the school curriculum [4]. Findings indicated that the use of the tablet devices improved the efficiency of teachers and the workflow of students with neither group constrained by time or space. Students reported being able to use multiple functions and applications of the iPad, namely: writing memos, calculating, and online information searches. For teaching staff, the device promoted technology leadership and efficacy - augmenting their ability to lead a technologically advanced teaching and learning space. Wireless technology tools, including tablets and smart phones, were identified by participants as "remarkably fashionable". Students and teachers were eager to use them, thus changing their worldview of learning and teaching. The authors maintain that exponential growth and adoption of wireless tools will shape learning and teaching practices in the near future. The availability of high-speed internet connection will be a primary factor in the efficient and effective use of this technology.

Morgan [5] explains how mobile learning can be enriched by utilizing audio visual methods of communication coupled with the technological facility to communicate. Referring to student engagement in education, Morgan deliberates on the use of handheld wireless devices such as laptops, tablets and smart phones. This study explores the additional utility of using mobile devices with publicly available applications such as mind mapping software and the WIKI collaborative platform. It reveals the popularity of social media platforms to further enrich the quality of mobile learning facilities.

Findings from the above studies suggest that mobile technologies in educational spaces are highly useful. This is primarily due to the quality returns from the devices utility; specifying, effective and efficient communicative methods are enriched by the technologies' convenient accessibility in time and space.

In an earlier study Liu, Wang, Liang, Chan, Ko and Yang [6] focused on the WiTEC technology platform which made use of integrated mobile learning devices, wireless communication and network technologies. These researchers uphold that the use of this technology makes delivery and learning more effective when compared with traditional teaching and learning. Liu et al. noted previous research demonstrating that highly interactive classrooms not only increase the utility rate of class computers but also enhance students' attention and interest in learning. This being the case, the possibilities for technology enhanced learning, and learning spaces, are vast. The benefits include stimulating curiosity in learning, an important factor contributing to deep learning. The goal here is to create learning and teaching spaces that promote understanding and application to real life - where educational objectives are realized, including subject and course level learning outcomes, and graduate attributes, capabilities and qualities. In addition, WiTEC technology enables the teacher to monitor each student's learning status so that teaching and learning activities can be adjusted and prompt feedback of assessment for learning can be given.

With respect to the introduction of on-line education in Singapore, Koh, Kin, Wadhwa and Lim [7] identify certain 
benefits of wireless learning technology: motivation for student learning, enhanced capacity for assimilation of knowledge, and greater knowledge retention of the subject matter. The researchers make reference to increases in motor coordination which arise due to stimulation caused by the activity of on-line game playing. They further explain 'push factors', which refer to the external forces influencing the utility of gaming; as well as 'pull factors', which refer to the internal motivating factors that stimulate teachers to utilize gaming in the field of education.

Tay, Lim, Lye, $\mathrm{Ng}$ and Lim [8] highlight the positive influence of learning with technology, referring to it as 'ease to learn'. These researchers conclude that the use of web 2.0 online social applications, in conjunction with open-source learning management systems, can be highly beneficial. They contend that success is due to the nature of the collaborative activities and teaching experiences that are derived when these technologies are put into practice.

However, the need for caution over the over-zealous and under-analyzed take up of wireless learning technology has been noted by Gay, Stefanone, Grace-Martin and Hembrooke [9]. The authors warn that wireless technology for educational purposes cannot be adequately understood and adopted through a onesize-fits-all mentality. They argue that different learning and teaching environments, course content, pedagogical models and curricular philosophies influence how wireless technologies can be used most effectively.

At this time of rapid change, both technologically and pedagogically, the paper by Gay et al. [9] is a sobering reminder of the importance of an integrative matrix for the analysis of new 'networked' spaces of learning. Such a thinking matrix involves the simultaneous consideration of philosophy, learning and teaching practice, learning space design, and wireless learning technologies - both mobile technologies and WLTs platforms.

\section{WLTs \& Spaces of Learning}

In recent years, there has been a paradigm shift from the traditional teacher-oriented to a more interactive, studentoriented, higher education environment. Engagement with, and participation of, students is prioritized, with teachers encouraging students to use familiar technology as part of their learning experience. While many new audio visual and IT related products have been developed to meet this demand, no one product has met all the needs of the contemporary classroom as effectively as Wireless Learning Technologies. Newly designed classrooms use a combination of students' individual mobile WLT gadgets with LCD screens connected to keyboards, computer consoles, WLT platforms, and Wireless LAN (Wi-Fi).

In a recent case study of a WLT classroom in Hong Kong, Salter, Thomson, Fox and Lam [10] evaluated the implementation of prototype technology-rich collaborative classrooms at the University of Hong Kong (HKU). The learning spaces were designed as a retro-fit of an existing studio. Through the development of collaborative learning spaces, the University hopes to provide an enhanced learning and teaching environment for both staff training - including training in teaching in the new space - and student learning.

The Salter et al. [10] team utilized an outcome-based approach to student learning (OBSL) to promote creative teaching methods and activities to meet learning objectives. The collaborative learning spaces were piloted in two subjects, each at a different course level: a new intermediate level Environmental Science subject and the Masters of Science in Information Technology in Education. The study reports positive feedback from the majority of students pertaining to the use of technology and collaborative interaction in the learning spaces.

Salter and colleagues [10] reviewed past studies that demonstrated the usefulness and effectiveness of technology rich collaborative learning space or 'networked' classrooms on the impact of students' learning. For instance, collaborative learning spaces have been found to strengthen social interaction between students and to maintain an active learning attitude during curriculum [11]. The collaborative learning spaces appear to promote greater interest towards the subject at hand which leads to a more positive learning attitude [11]. In addition, recommended features of a well-designed learning space have been studied. This includes deviation from traditional classrooms where only one focal point is available by clustering students around separate tables rather than in rows in order to promote a multi-focal classroom setting [12] [13]. The installation of movable furnishings, grouped settings with LCD screens and compatible WLTs were among the many aspects reviewed in the paper.

This informative and well-written paper did not, however, give details of the specific WLT systems used in the learning space. As 'networked' spaces of learning involve the notion of networks on the multiple levels of: student-to-student collaboration and interaction invited through the clusters of work tables; networked WLT mobile gadgets; and WLT platforms within the learning space, further research could usefully explore learning spaces through this inclusive notion of networks [2].

\section{A LEARNING SPACE AT JCU SINGAPORE}



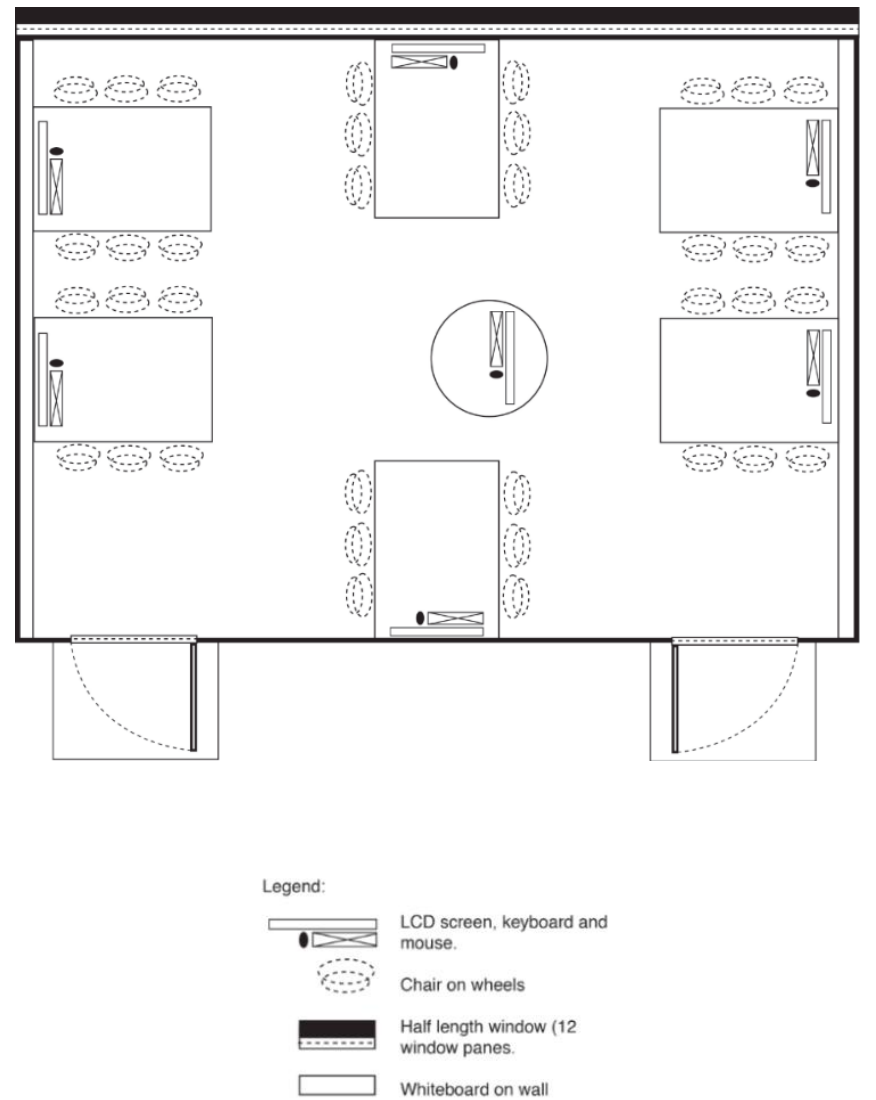

Fig. 1. JCU Singapore learning space using ProVEOS WLT system.

James Cook University (JCU) has set up several new purposely designed 'networked' spaces of learning across its three 'tri-city' tropical campuses: Townsville and Cairns, in North Australia, and its capital city campus in Singapore. Similar to HKU, the new model classrooms at JCU Singapore have been retrofitted. Currently the campus has two technology enhanced collaborative learning spaces. One uses Apple WLT and the other uses the ProVEOS WLT system developed by the Singaporean company WOW Vision. The second room is outlined here.

This learning space is rectangular with two doors along one length of the room and a bank of windows along the opposite wall. The room consists of six tables that jut out from the four walls like rectangle satellite-isles. Six chairs on rollers are arranged three either side of each table. Above each table hangs a large 40-inch LCD screen it is wire connected to a keyboard and mouse which rests on the table's surface. Across the breadth of two walls of the room run long whiteboards. The new 'networked' room is covered with a designated Wireless LAN
(Wi-Fi) which students and academics can connect to using their mobile devices in order to project their work wirelessly on the LCD screen. However, not all mobile devices are compatible with the ProVEOS wireless learning technology. For instance, the installed WLT system does not support iPad. As all fulltime students and academics are issued with iPads at the JCU Singapore campus, this non-compatibility is a problem. Laptops and smarts phones are compatible. Alternatively the keyboard and mouse attached to each LCD screen allows a 'designated driver' at each table to edit work directly on the screen with input from the student team. The room is well lit from the bank of windows installed at table level, blinds soften the tropical sun, and combined with the monochromatic grey-scale of the room, allows the space to feel light and airy. This sense of space is enhanced by the view out of the window. The room is on the third level and a glance outside takes in the tops of clumping palms, a small green, the next block of classrooms, the tall hedge that surrounds the campus, a wide road with its median strip planted with raintrees, and across the road, the fronts of residential terrace houses [2].

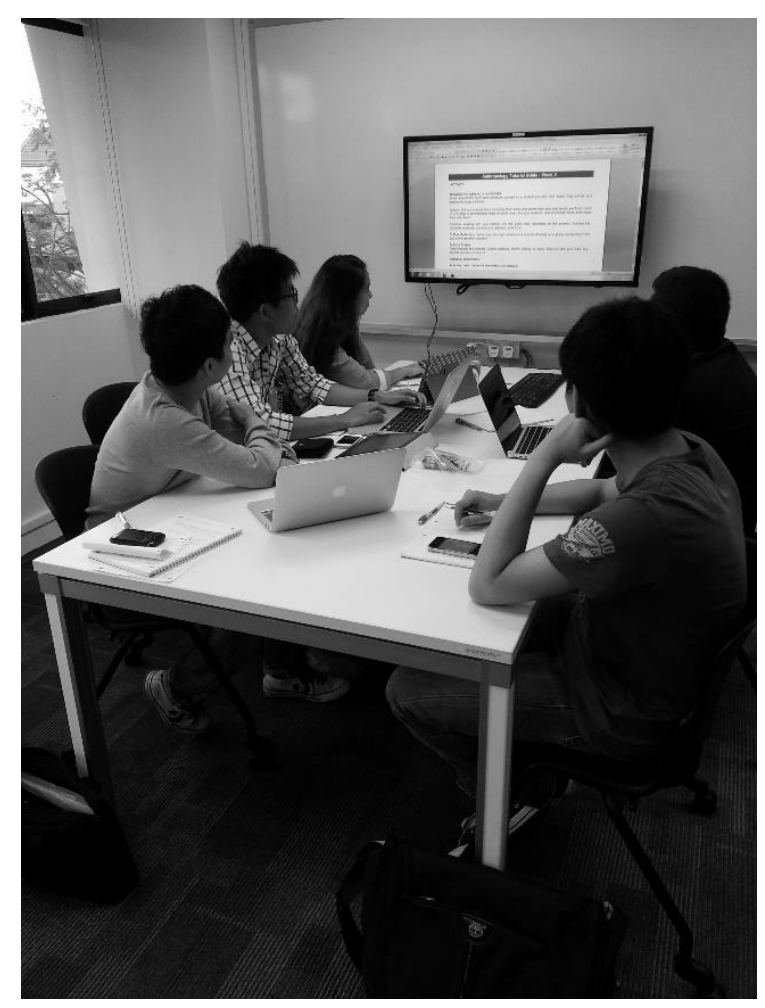

Fig. 2. JCU Singapore learning space student team work. 
Similar to the case study conducted by Salter and colleagues [10], a team of academics from JCU are researching the new 'networked' learning space. The cross-disciplinary team consists of representatives from Arts and Social Sciences, Business, Tourism and Information Technology, and Education. As part of their study they will undertake surveys of students use and experience of the 'networked' classroom, this will include perceptions of space, learning experiences, and the use of the WLT platform installed in the learning space.

Designated subjects from first year to graduate level have been identified for the study. The academics will also explore scenarios of learning that arise from the specifics of desired subject and disciplinary learning outcomes. Thus indicating the potential variety of ways in which the one 'networked' classroom can be used.

Like the Hong Kong case study, the new 'networked' classrooms at JCU Singapore are still being trialed. And academics we are still discovering the affordances of these spaces of learning - both spatially and technologically.

\section{REVIEW OF WLTS}

A WLT platform is marketed as providing solutions for shared access to a display or projector to facilitate interaction and comparison, moving seamlessly from one presenter to another. Any wireless AV solution should be easy to use, easy to maintain and be cost effective. It should support an unlimited number of users with both a wired or wireless connection or by extending to other sites using a VPN connection. With scalable solutions to suit every size of application, the WLT should offer a choice of products which are all packed with innovative features. These are strong reasons to justify the reliance of government, military, transportation networks, hospitals and businesses on WLT - and their growing use in education.

WLTs have been widely used in several higher education institutions across the globe. For example, the ProVEOS platform is operational in the following locations: North Carolina University, University of Southern California [14], James Cook University (Singapore/Australia), and Republic Polytechnic, Singapore [15].

\section{WLT Systems in Singapore}

Wireless presentation solutions in Singapore are used in education, retail, finance, hospitality and healthcare. The education segment covers the basic to advance wireless presentation network and collaboration requirement. Wireless learning technologies for education are available from: Apple, Microsoft, Jackson, Thinkwave and WOW Vision. The other smaller players in the Singapore market include Kramer, Avaya, InFocus, WiJet Video and Aver.

Table I presents a comparison of major WLTs available in Singapore. It outlines the product, manufacturer and the platform. The comparison is of WLTs designed for use by adults and thus suitable for use in higher education scenarios.
TABLE I.

\begin{tabular}{|l|l|l|l|l|}
\hline \multicolumn{1}{|c|}{ Name } & Manufacturer & Platform & \multicolumn{1}{|c|}{ Price } & Grade \\
\hline ClarisWorks & Apple & Mac & NA & Adult \\
Excel & Microsoft & Windows & 339 & Adult \\
Grade Quick & Jackson & Windows & 70 & Adult \\
Thinkwave & Thinkwave & Windows & 80 & Adult \\
ProVEOS & WOW vision & Windows & NA & Adult \\
\hline
\end{tabular}

In order to ascertain the usefulness of the WLTs, an early study by Starr [16] undertook to compare the wireless learning technology systems. Using a content analysis approach, the paper evaluated the WLT solutions available in Singapore. The attributes for comparison included: installability, usability, performance, usefulness and vendor support. These factors were considered the most common in decision-making processes regarding buying and using a WLT system (see Table II).

This set of attributes was further assessed against an evaluation scale of 1 to 5 , where 1 indicates very disatisfactory, 2 disatisfactory, 3 average, 4 satisfactory, and 5 very satisfactory. The ratings were carried out by members of the Education World Tech Team which include educationaltechnology professionals who volunteer to contribute their knowledge and expertise to occasional papers made available on the Education World website. The results of the 2001 survey are tabulated below:

TABLE II

\begin{tabular}{|l|l|l|l|l|l|}
\hline \multicolumn{1}{|c|}{ Name } & Install & Usability & Perfom & Usefulness & Support \\
\hline ClarisWorks & 4 & 3 & 4 & 4 & 0 \\
Excel & 4 & 3 & 4 & 4 & 3 \\
Grade Quick & 3 & 3 & 3 & 4 & 3 \\
Thinkwave & 4 & 4 & 5 & 5 & 5 \\
\hline
\end{tabular}

Source : http://www.educationworld.com/a_tech/tech109.shtml

These findings on ClarisWorks, Excel, Grade Quick and Thinkwave are published by Education World and are available on the World Education site (www.worldeducation.com) a free online resource for comparative analysis of WLT platforms. It should be noted that the online resource is managed by a company that provides a WLT platform and therefore it is difficult to verify if the papers published on the site are entirely independent. Nevertheless, the criteria of usability of the WLT platforms and the five point scale of this 2001 study can be used to match findings and evaluate the latest WLTs.

The ProVEOS WLT solution designed in Singapore and being trialed in the 'networked' classrooms of James Cook University's three tropical campuses, including the offshore campus JCU Singapore, does not feature in the World Education evaluation which was undertaken in 2001, well before the development of this system. However, a short survey, administered after an academic and professional staff training workshop in the use of the ProVEOS WLT system at JCU Singapore, utilized the same criteria to ascertain preliminary feedback on the WLT system. The findings of the survey of 
fifteen respondents were based on the same scale as the Starr data [16].

TABLE III.

\begin{tabular}{|l|l|l|l|l|l|}
\hline & Install & Usability & Perfom & Usefulness & Support \\
\hline ProVEOS & 5 & 4 & 5 & 5 & 5 \\
\hline
\end{tabular}

Source : based on a survey of 15 respondents at JCU Singapore at the conclusion of a ProVEOS training workshop.

The comparison indicates that the perception of performability of this WLT system ranks well in comparison to other WLTs in terms of installability, usability, performance, usefulness and support [1]. Except for usability, the rest of the attributes score very high. Although the 'usability' criterion ranks comparative with the other highest ranking WLT system, it does not score as high as the other attributes. The lower score for usability indicates a problem with the friendliness of the user interface. This is mainly due to a lack of an icon based user interface. The ProVEOS system employs a text-based interface; this overuse of text reduces user experience. In addressing this issue, WOW Vision has recently launched their latest flagship WLT named Collab8. The product aims to further enhance collaboration through embracing an icon based user interface, among other features. Although the project team has had the opportunity to view the new product, we have not yet been able to test it in prolonged classroom scenarios. It also needs to be stressed that the small survey of the ProVEOS system was conducted among staff being introduced to the new space of learning and trained in the WLT. It did not survey student perception or engagement. This further study is the aim of the research project initiated by the authors of this paper.

The authors suggest that further evaluation of the WLT aspects of collaborative learning spaces is required.

\section{CONCLUSION}

WLT has grown immensely over the last decades - and continues to undergo rapid change. It has contributed to more efficient and effective learning and teaching environments in higher education. WLT has helped both students and teachers in the education industry by allowing learning technologies to go wireless. These technologies are integral to the new technologically enhanced collaborative spaces of learning being developed in universities around the globe. Both mobile WLTs and classroom platforms offer the potential for innovative ways of teaching and learning. However, these technologies need to be assessed and understood in relation to the spaces of learning themselves and to specific disciplinary and curricula scenarios. An analytical matrix that considers each of these aspects as a network of observation and analysis is still in its early stages. Cross-disciplinary academic teams are beginning to take up this challenge as part of their own research-teaching nexus.

\section{ACKNOWLEDGMENT}

The authors would like to thank the Project Officer and Research Assistant, Crystal Tang, for her editing work on this paper and especially for the line drawing of the new space of learning at JCU Singapore campus.

\section{REFERENCES}

[1] Teoh, T. T., Bhati, A., Lundberg, A. \& Carter, M. (2013). Evaluating New Learning Technology in Asia: Singapore as a case study. Proceedings of the $3^{\text {rd }}$ Annual International Conference on Education and e-Learning (EeL) pp. 63-66.

[2] Lundberg, A. (in press). Get Connected! Collaborative Adventures in Networked Spaces of Learning. Porceedings of the $2^{\text {nd }}$ International Conference ERPBSS, Dubai, UAE.

[3] Mueller, J., Wood, E., Pasquale, D. \& Cruikshank, R. (2012). Examining mobile technology in higher education: Handheld devices in and out of the classroom. International Journal of Higher Education, 1(2)

[4] Ross, S.M., Morrison, G.R., \& Lowther, D.L. (2010). Educational Technology Research Past and Present: Balancing Rigor and Relevance to Impact School Learning. Contemporary Educational Technology, 1(1), 17-35.

[5] Morgan, H. (2010). Using handheld wireless technologies in school: Advantageous or disadvantageous? Childhood Education, 87(2), 139.

[6] Liu, T. C., Wang, H. Y., Liang, J. K., Chan, T. W., Ko, H. W. and Yang, J. C. (2003). 'Wireless and mobile technologies to enhance teaching and learning' Journal of Computer Assisted Learning, 19, 371-382.

[7] Koh, E., Kin, Y. G., Wadhwa, B., \& Lim, J. (2012). Teacher perceptions of games in Singapore schools. Simulation \& Gaming, 43(1), 51-66.

[8] Tay, L. Y., Lim, C. P., Lye, S. Y., Ng, K. J., \& Lim, S. K. (2011). Opensource learning management system and web 2.0 online social software applications as learning platforms for an elementary school in Singapore. Learning, Media and Technology, 36(4), 349-365.

[9] Gay, G., Stefanone, M., Grace-Martin, M. \& Hembrooke, H. (2001). The effects of wireless computing in collaborative learning environments. International Journal of Human-Computer Interaction, 13(2), 257276.

[10] Salter, D., Thomson, D. L., Fox, B., \& Lam, J. (2013). Use and evaluataion of a technology-rich experimental collaborative classroom. Higher Education Research \& Development, 32(5), 805-819.

[11] Dori, Y. J., \& Belcher, J. (2005). How does technology-enabled active learning affect undergraduate students' understanding of electromagnetism concepts? Journal of the Learning Sciences, 14(2), 243-279.

[12] Taylor, S. S. (2009). Effects of studio space on teaching and learning: Preliminary findings from two case studies. Innovative Higher Education, 33(4), 217-228.

[13] Whiteside, A., \& Fitzgerald, S. (2008). Designing spaces for active learning. Implications, 7(1), 1-6.

[14] YouTube. (29 March 2011). USC speaks about ProVEOS and its use in collaboration spaces. Retrieved from http://www.youtube.com/watch? $=\mathrm{kNrneCnax} 14 \&$ feature=youtu.be

[15] AS Audio. (10 August 2103). Helping Republic Polytechnic achieve the forefront of education. Retrieved from http://www.asaudio.com/en/republic-polytechnic-singapore-

[16] Starr, L. (12 December 2001). Load 'Em Up: Classroom-Management Software Picks. Education World. Retrieved from http://www.educationworld.com/a tech/tech109.shtml 


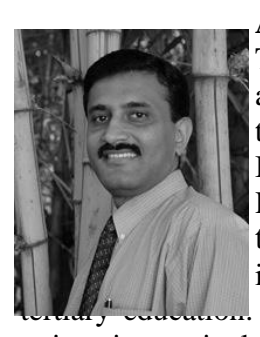

Abhishek Bhati is Associate Dean of Business, Tourism and IT. He is responsible for overseeing academic administration and introducing strategies to enhance student experience for the School of Business programs offered in Singapore Campus. His wide research portfolio includes the researchteaching nexus areas of incorporating 'work integrated learning' (WIL) based strategies in A recent project involved implementing WIL in university curriculum. He is a member of the Faculty WIL workgroup. He has been Fellow in Residence at The Cairns Institute and is a member of JCU Teaching and Learning Academy.

Anita Lundberg is a cultural anthropologist. Her current research focus is the anthropology of higher education -

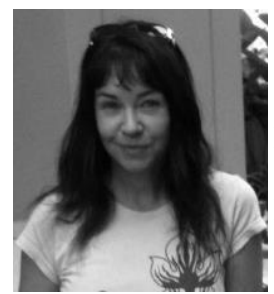
from global education hubs to spaces of learning. Dr Lundberg is a member of the CNRS research group LIA TransOceanik (CNRS, Collège de France \& JCU). She is a Fellow of The Cairns Institute and a Member of the Teaching and Learning Academy. She has previously been a Post-Doctoral Fellow, Cambridge University, UK; a Guest Researcher with the Maison AsiePacifique, Université d'Aix-Marseille; and a Visiting Fellow with the Institute of the Malay World and Civilization, National University Malaysia. She was also an Anthropologist-in-Residence at Rimbun Dahan, Malaysia. Her PhD in Anthropology is complimented by an MA (Hons) in Science and Technology Studie

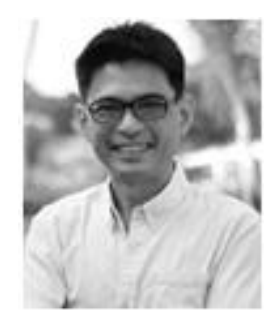

Teoh Teik Toe is a chartered holder of ACCA, CIMA and CFA. He is a Chartered Accountant of Malaysia, Chartered Accountant in Singapore and CPA in Australia. Dr Teoh graduated from the University of Southern California with a Bachelor in Electrical Engineering and later a Master in Computer Engineering. He has completed a Bachelor of Law from Birmingham City University, Master of Business from the University of Newcastle, MBA from University of Southern Queensland, Master of Accounting and Finance from University of Gloucestershire and $\mathrm{PhD}$ in Computer Engineering from Nanyang Technological University. He is also a member of Mensa.

Margaret Carter has been involved with education system renewal

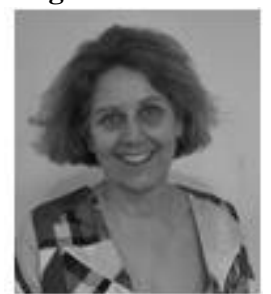
programs, designing and implementing blended and online learning curriculum, community based social education programs, mentoring programs, and curriculum texts for children on the autistic spectrum.Dr Carter has presented keynote addresses, conference papers and written journal articles across a range of disciplines and in a variety of professional learning contexts. She is the author of several books, including Young Children's Social Behaviour and Take a Stand, Lend a Hand - Stop Bullying Now. She has also coauthored student texts including Set for Success and Friendly Facts as well as consultancy and parenting programs. 